\title{
Characterization of Titanium Dioxide Coatings Obtained by Vacuum-arc Deposition
}

\author{
Anton Taran ${ }^{1}$, Igor Garkusha ${ }^{1,4}$, Alexander Timoshenko ${ }^{1}$, Valerij Taran ${ }^{1}$, Ivan Misiruk ${ }^{1}$, Tamara Skoblo ${ }^{2}$, \\ Svetlana Romaniuk ${ }^{2}$, Taras Maltsev², Vadym Starikov³, Alexey Baturin ${ }^{3}$, Yurij Gnidenko ${ }^{4}$ \\ ${ }^{1}$ National Science Center "Kharkov Institute of Physics and Technology" (NSC KIPT), Institute of Plasma Physics, \\ Kharkov, Ukraine \\ ${ }^{2}$ National Technical University of Agriculture, Kharkov, Ukraine \\ ${ }^{3}$ National Technical University "Kharkov Polytechnical Institute",Kharkov, Ukraine \\ ${ }^{4}$ Karazin State University, Kharkov, Ukraine \\ Email: avtaran@ukr.net
}

\begin{abstract}
TiO}_{2}$ coatings on AISI 430 stainless steel were produced by the vacuum-arc deposition technique with the application of modified curvilinear magnetic filter allowed enhanced deposition rates up to $50 \mathrm{\mu m} /$ hour decreasing the amount of macroparticles. The structure, chemical and phase composition of the obtained coatings was investigated using SEM with EDX, XRF and XRD analysis. According to X-ray diffraction analysis, the formation of stoichiometric $\mathrm{TiO}_{2}$ phase took place. The mechanical and tribological properties were established. The obtained coatings had average nanohardness of $13.8 \mathrm{GPa}$ and Young's modulus of $211 \mathrm{GPa}$. Dry friction wear tests revealed high resistance of the coating to wear showing low friction coefficient under a load of $50 \mathrm{~N}$. The statistical results of photo-catalytic activity showed a significant decrease of E.coli colonies on samples coated with $\mathrm{TiO}_{2}$ during 20 min UV exposure format.
\end{abstract}

Keywords: Titanium dioxide, structure, vacuum-arc deposition, coating, phase composition, nanohardness, photocatalytic activity

\section{Introduction}

Titanium dioxide $\mathrm{TiO}_{2}$ has many potential applications as a coating including medical technology; wear protection, due to non-toxicity, high photocatalytic activity, and strong self-cleaning ability [1].

Titanium dioxide is a well-known photocatalyst in presence of UV light. A substantial amount of literature has been published on the effect of photocatalytic $\mathrm{TiO}_{2}$ nanoparticles on microorganisms $[2,3]$. According to the literature data $\mathrm{TiO}_{2}$ on stainless steel reduces bacterial activity of E.coli by $99 \%$. This provides an effective antimicrobial surface coating method for medical implements thereby reducing the risk of hospital-acquired infections [4]. The efficiency of photocatalytic disinfection is attributed to the oxidative damage mainly induced by reactive oxygen species (ROS), such as $\mathrm{O}_{2^{-}}, \mathrm{H}_{2} \mathrm{O}_{2}$ and HO-. These reactive oxygen species are produced by redox reactions between adsorbed species (such as water and oxygen) and electrons and holes photo-generated by the illumination of $\mathrm{TiO}_{2}$.

$\mathrm{TiO}_{2}$ films were prepared by various methods, such as chemical vapor deposition, pulsed laser deposition, sol-gel deposition, spray pyrolysis; plasma enhanced chemical vapor deposition and DC/RF magnetron sputtering [5-9].

It is well known that the method of vacuum-arc deposition provides a wide variation of the microstructure and hardness of coatings by changing the grain size, crystallographic orientation, lattice defects, texture, as well as surface morphology and phase composition [10-14]. The factors that have limited the applications of PVD coatings as complete barriers to corrosion are the presence of coating defects such as pinholes, voids, cracks and macro-particles.

In so doing, a new source of filtered vacuum arc plasma was used providing transportation to the condensation surface of at least $60 \%$ of the current of ions emitted by cathode spots. This is 1.5 times higher than that of known analogues. Deposition rate reaches several tens of microns per hour that is comparable to traditional sources of unfiltered plasma. The area occupied by macroparticles is less than $0.2 \%$ of total area of coating per $1 \mu \mathrm{m}$ of its thickness. 
In this research $\mathrm{TiO}_{2}$ coatings were deposited onto AISI 430 SS surface using vacuum-arc evaporation method using modified curvilinear filter. The structure, chemical and phase composition of the obtained coatings have been investigated. The mechanical and tribological properties have also been established. Photocatalytic activity of $\mathrm{TiO}_{2}$ coatings have been tested under UV exposure.

\section{Experimental}

Polished stainless steel samples of $25 \times 25 \times 3 \mathrm{~mm}$ size were used as the substrate material (roughness $\mathrm{Ra} \approx 0.09 \mu \mathrm{m})$. The chemical composition of stainless steel substrate was monitored by portable XRF analyzer of Z-300 LIBS type by SciAps corp. (USA) and presented in Fig.1.

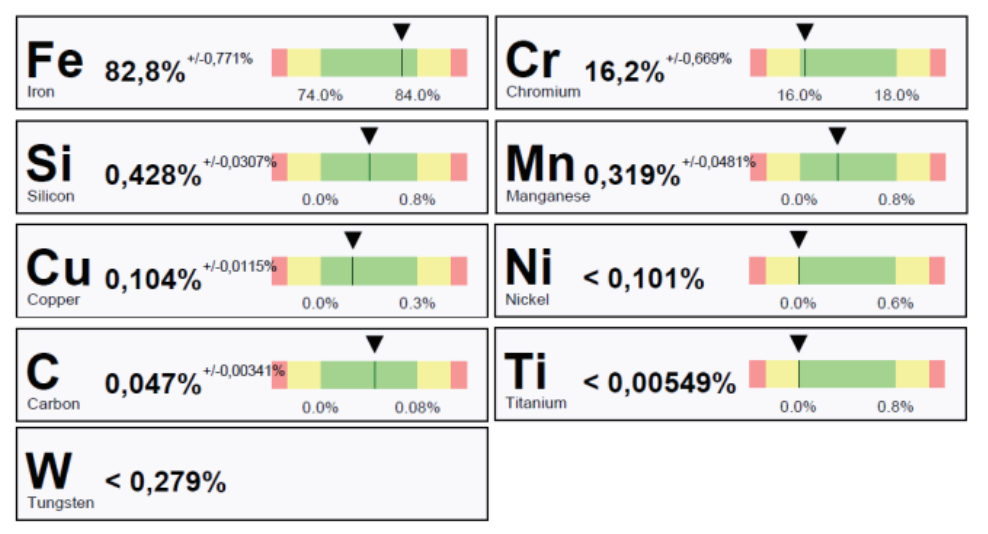

Figure 1. Chemical composition of AISI 430 stainless steel.

$\mathrm{TiO}_{\mathrm{x}}$ coatings were synthesized using vacuum-arc deposition in Bulat- type device. The scheme of experimental equipment is shown in Fig.2. To apply coatings the chamber was evacuated to a pressure of $1 \times 10^{-4}$ Torr. First, the pulsed negative bias of 1000 volts with a frequency of $50 \mathrm{kHz}$ was applied to the sample holder. Vacuum arc was ignited $(\mathrm{Id}=105 \mathrm{~A})$ and the samples were cleaned by titanium ions in the pulsed mode for $1.5 \mathrm{~min}$. Next, the chamber was filled with oxygen to a pressure of about $4 \times 10^{-3}$ Torr and titanium dioxide was deposited during 10 minutes. Deposition rate was $50 \mu \mathrm{m} / \mathrm{h}$.

The surface topography of the coatings was studied using JEOL JSM-6390LV (USA) scanning electron microscope (SEM) with an accelerating voltage of $20 \mathrm{kV}$, chemical composition was examined using EDX analysis.

Energy-dispersive spectrometer SPRUT-K (AO Ukrrentgen, Ukraine) was used for X-ray fluorescent analysis. Spectrometer was equipped with $\mathrm{Si}(\mathrm{Li}) \mathrm{X}-100$ detector (Amptek, USA) in the arrangement with a $\mathrm{Si}$ and $\mathrm{KCl}$ secondary target. An X-ray tube BS-22 with shooting-through type Ag anode was applied. The thickness of $\mathrm{TiO}_{2}$ coating according to XRF data comprised $5 \mu \mathrm{m}$.

$\mathrm{X}$-ray diffraction (XRD) analysis were performed using DRON-3M device, under $\mathrm{Cu}-\mathrm{K} \alpha$ radiation, monohromated by (002) HOPG in diffracted beam. The XRD line scans were performed in $\theta-2 \theta$ scanning mode where the incident angle $\theta$ and diffracted angle $2 \theta$ are scanned simultaneously. The crystallite size was determined from the broadenings of corresponding X-ray spectrum peaks by using Scherrer's formula.

The nanohardness was measured by Nanoindenter G200 (USA). The loading and unloading rates of the nanoindentation were $10 \mathrm{mN} / \mathrm{min}$. Samples were tested to a depth of $500 \mathrm{~nm}$. The distance between prints were $15 \mu \mathrm{m}$ and for each sample was made 7 prints.

Tribological properties of the coating were carried out using ball-on-disc method on SMT-1 type machine. The rotation frequency of the rollers (counterbody) was $500 \mathrm{~min}^{-1}$. Sample loading was performed at $50 \mathrm{~N}$ and $100 \mathrm{~N}$. The duration of each stage was 5 minutes. Lubrication conditions were dry friction. Material of the roller was $100 \mathrm{Cr} 6$ steel. The wear and microhardness of the sample were measured after two stages. At the same time, the coefficient of friction was fixed at each stage. 


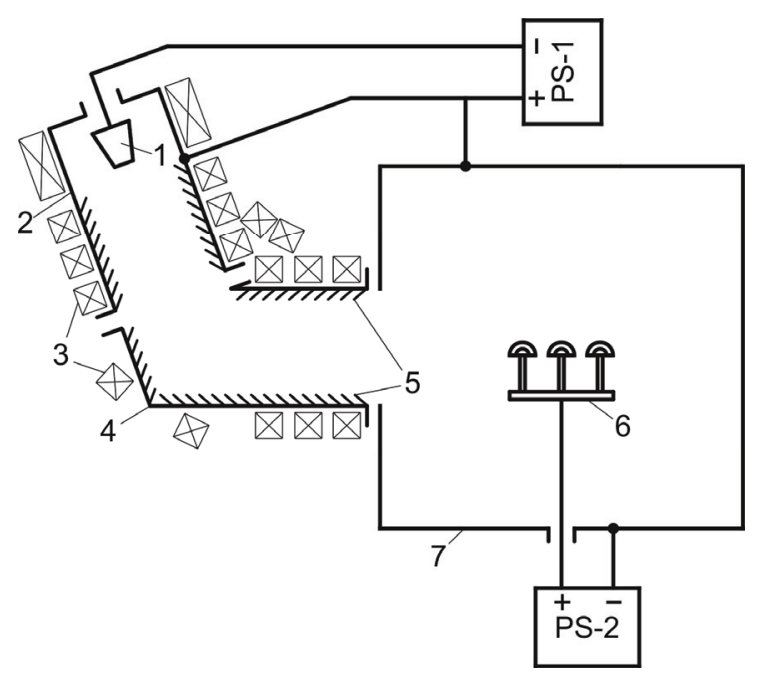

Figure 2. Scheme of experimental equipment: 1 - cathode; 2 - anode; 3 - electromagnetic coils; 4 - duct; 5 baffles; 6 - samples; 7 - vacuum chamber; PS-1 - arc discharge power supply unit; PS-2 - source of pulsed negative bias.

\section{Results and Discussion}

The chemical and phase composition of the coating were studied by X-ray diffraction analysis and energy-dispersive X-ray spectroscopy EDX. The XRD and EDX patterns of $\mathrm{TiO}_{2}$ are shown in Fig.3a, b. The diffraction peaks indicate the formation of crystallized $\mathrm{TiO}_{2}$ coating with some strong Fe peaks from the substrate material. XRD analysis revealed the existence of $\mathrm{TiO}_{2}$ phase only (in accordance with JCPDS card 21-1236) with lattice parameters $(a=4.531 ; b=5.498 ; c=4.900)$ (Fig.3a).
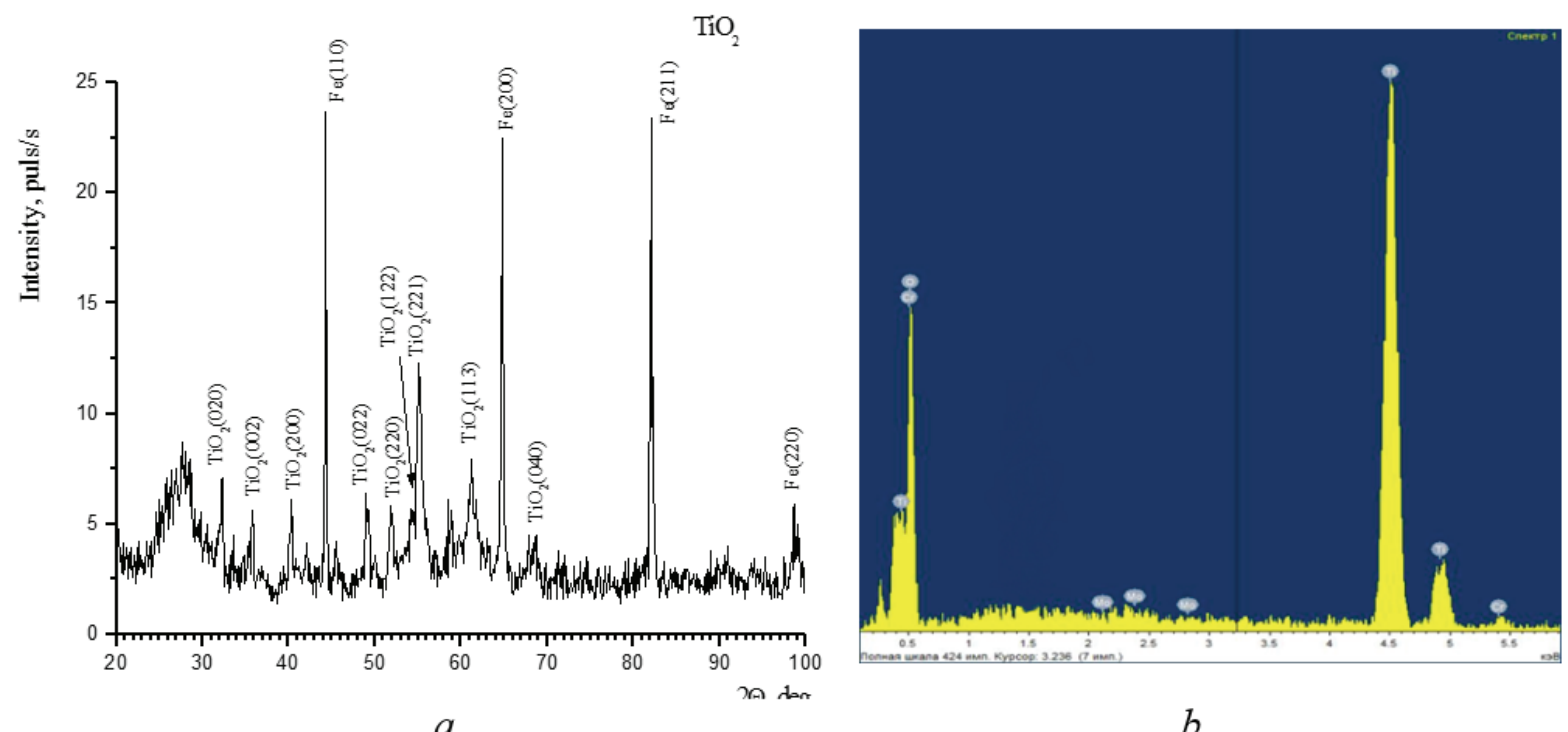

$b$

Figure 3. XRD pattern (a) and EDX spectrum (b) from $\mathrm{TiO}_{2}$ coating on AISI 430 SS

No additional phases have been observed. The EDX spectrum consisted the characteristic peaks of titanium and oxygen and low $\mathrm{Cr}$, Fe, Si peaks from the substrate material (Fig.3b.). The chemical content was $\mathrm{Ti}=29.54$ at. $\%$ and $\mathrm{O}=69.40$ at. $\%$ (Tab.1). It indicates that the deposited films were stoichiometric. There was no variation in the chemical composition in the coating. 
Table 1. Chemical composition of $\mathrm{TiO}_{2}$ coating in accordance with EDX

\begin{tabular}{ccc}
\hline Element & wt\% & at\% \\
\hline $\mathrm{O}$ & 43.00 & 69.40 \\
$\mathrm{Ti}$ & 54.79 & 29.54 \\
$\mathrm{Cr}$ & 1.40 & 0.69 \\
$\mathrm{Fe}$ & 0.81 & 0.37 \\
\hline
\end{tabular}

The crystallite size of the deposited $\mathrm{TiO}_{2}$ coatings was calculated from the full width at half maximum intensity $(\beta)$ (FWHM) of the X-ray diffraction angle $(\theta)$ of the peak and the wavelength $(\lambda)$ of copper X-ray radiation using Debye-Scherrer's relation taking into consideration that no strains were developed in the films.

$$
\mathrm{D}=\mathrm{K} \lambda / \beta \cos \theta
$$

where, $\mathrm{K}$ is a constant with the value of 0.9 for copper X-ray radiation and $\theta$ the diffraction angle. Crystallite size of the titanium dioxide film was $21 \mathrm{~nm}$.

The surface morphology of deposited $\mathrm{TiO}_{2}$ coating was investigated. Fig. 4a-c shows SEM images of $\mathrm{TiO}_{2}$ coating at various magnifications.
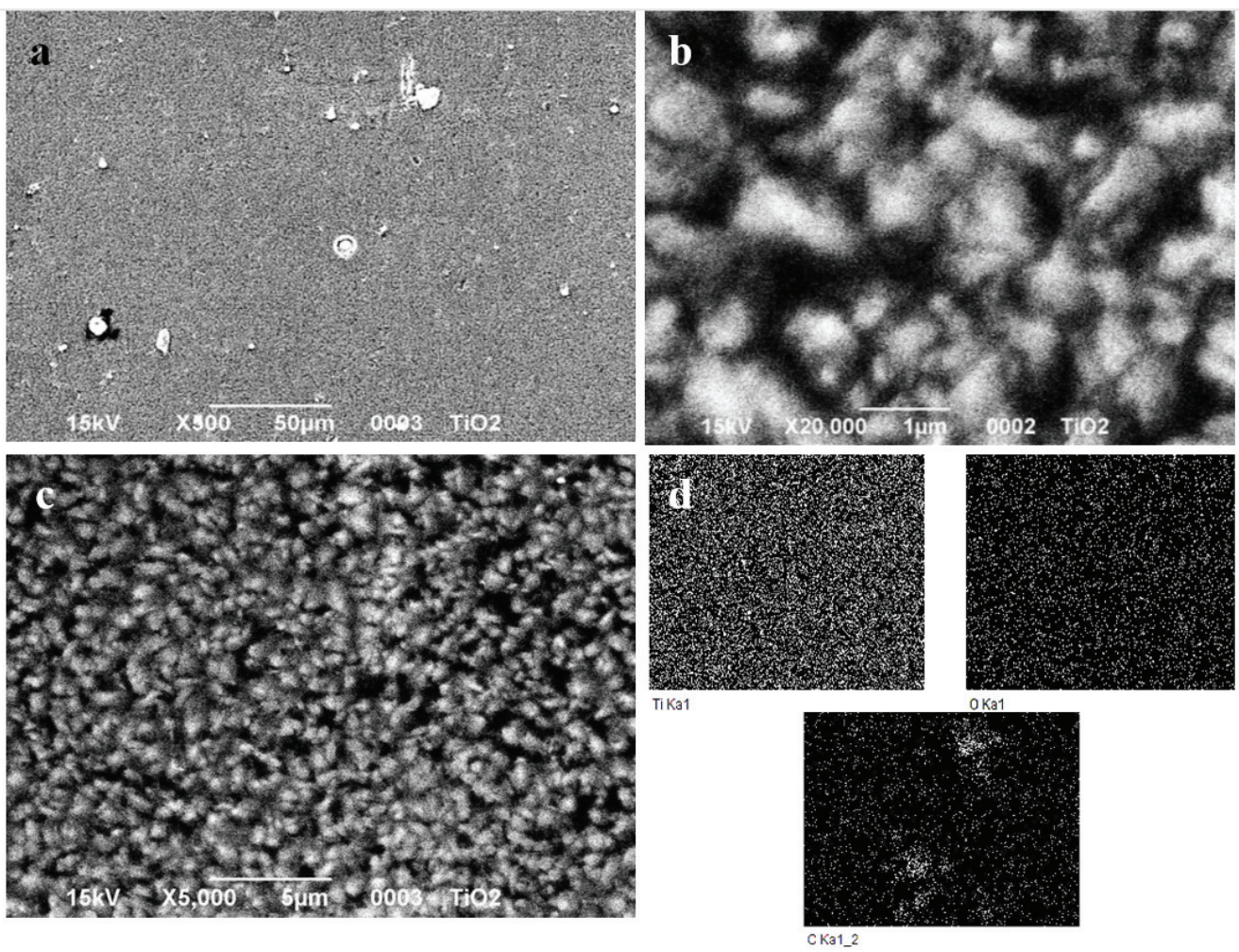

Figure 4. SEM images (a-c) and EDX mapping (d) of $\mathrm{TiO}_{2}$ coating on AISI 430.

The quality of the coating revealed very low amount of macroparticles distributed over the surface. The coating composed of relatively small globular $\mathrm{TiO}_{2}$ nanoparticles aggregated to form clusters. EDX mapping of distribution of chemical elements over the surface is shown in Fig.4d.

\subsection{Mechanical Properties}

The $H / E$ ratio is a criterion of the plastic index of the materials, and a small ratio supports elastic deformation during contact motion and is therefore beneficial for enhancing the tribological performance of the material. The $H^{3} / E^{* 2}$ ratio (where $E^{*}=E /\left(1-\mu^{2}\right)$ - the effective elastic modulus; $\mu$ - Poisson's ratio) 
are qualitative comparative characteristic of the plastic deformation resistance of the material. The nanoidentation diagrams for $\mathrm{TiO}_{2}$ coating are presented in Fig. 5. The results of $H$ and $E$ values for 7 prints are summarized in Tab.2. According to nanohardness tests, the average value of nanohardness for $\mathrm{TiO}_{2}$ was $13.8 \mathrm{GPa}$ with the data spread $9.53 \%$. The average value of elastic modulus was $211.072 \mathrm{GPa}$. The data spread does not exceed $7.71 \%$.

The shear modulus $(G)$ and yield stress $\left(\sigma_{T}\right)$ are defined as $G=E / 2 \times(1+\mu) ; \sigma_{T}=H \mu / 3($ Tab.2,3).

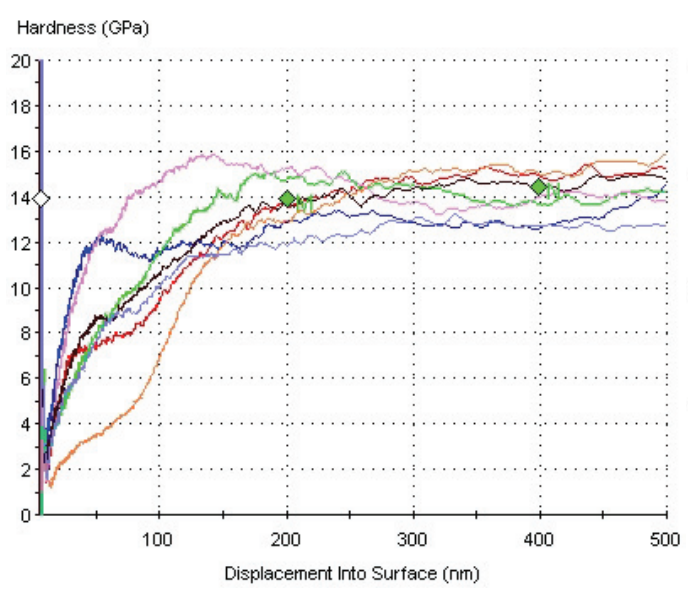

$a$

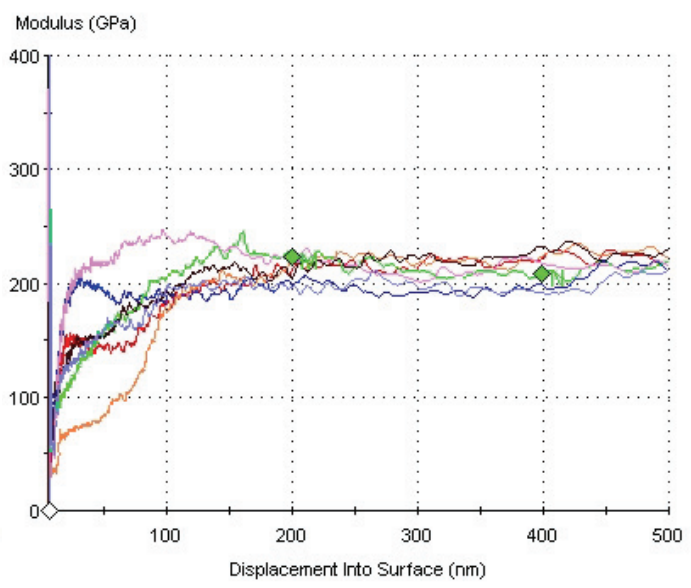

$b$

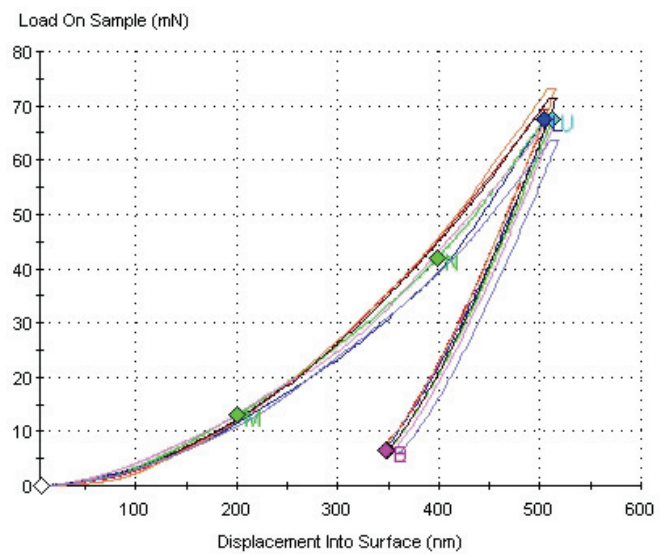

Figure 5. Nanoidentation diagrams for the $\mathrm{TiO}_{2}$ coating: nanohardness (a), elastic modulus (b), load-unload diagram (c).

Table 2. The results of $\mathrm{TiO}_{2}$ coating mechanical test

\begin{tabular}{ccccccc}
\hline Test & $E, \mathrm{GPa}$ & $H, \mathrm{GPa}$ & $H / E$ & $H^{3} / E^{k_{2}}$ & $G, \mathrm{GPa}$ & $\sigma_{T}, \mathrm{GPa}$ \\
\hline 1 & 216.814 & 14.515 & 0.067 & 0.057 & 135.51 & 4.83 \\
2 & 194.802 & 12.956 & 0.067 & 0.050 & 121.75 & 4.31 \\
3 & 214.05 & 14.36 & 0.067 & 0.057 & 133.78 & 4.78 \\
4 & 220.587 & 14.447 & 0.065 & 0.054 & 137.87 & 4.81 \\
5 & 214.036 & 14.114 & 0.066 & 0.054 & 133.77 & 4.70 \\
6 & 219.956 & 14.214 & 0.065 & 0.052 & 137.47 & 4.73 \\
7 & 197.258 & 12.558 & 0.064 & 0.045 & 123.29 & 4.18 \\
\hline Average & 211.072 & 13.881 & 0.066 & 0.053 & 131.92 & 4.62 \\
\hline
\end{tabular}


Table 3. Mechanical properties of AISI 430

\begin{tabular}{ccccccc}
\hline Test & $E, \mathrm{GPa}$ & $H, \mathrm{GPa}$ & $H / E$ & $H^{3} / E^{* 2}$ & $G, \mathrm{GPa}$ & $\sigma_{T}, \mathrm{GPa}$ \\
\hline 1 & 204.382 & 3.915 & 0.019 & 0.001 & 127.74 & 1.30 \\
2 & 217.567 & 5.01 & 0.023 & 0.002 & 135.98 & 1.67 \\
3 & 204.496 & 3.727 & 0.018 & 0.001 & 127.81 & 1.24 \\
4 & 184.049 & 4.084 & 0.022 & 0.002 & 115.03 & 1.36 \\
5 & 203.588 & 3.872 & 0.019 & 0.001 & 127.24 & 1.29 \\
6 & 205.773 & 3.99 & 0.019 & 0.001 & 128.61 & 1.33 \\
7 & 198.272 & 3.61 & 0.018 & 0.001 & 123.92 & 1.20 \\
\hline Average & 202.590 & 4.030 & 0.020 & 0.001 & 126.62 & 1.342 \\
\hline
\end{tabular}

\subsection{Tribological Behavior}

Tribological properties of the coating were carried out using ball-on-disc method on SMT-1 type machine. After friction and wear testing of the $\mathrm{TiO}_{2}$ coating, the results of weight wear and friction coefficient evaluation were obtained (tab. 4 and 5). Table 6 presents the values of the initial microhardness and after two-stage loading.

Table 4. The level of weight wear

\begin{tabular}{cccc}
\hline \multirow{2}{*}{ No. } & \multirow{2}{*}{ Coating } & \multicolumn{2}{c}{ Weight wear of, $\mathrm{g}$} \\
\cline { 3 - 4 } & & coating & roller \\
\hline 1 & $\mathrm{TiO}_{2}$ & -0.0116 & -0.0074 \\
\hline
\end{tabular}

Table 5. $\mathrm{TiO}_{2}$ coating microhardness

\begin{tabular}{cccc}
\hline \multirow{2}{*}{ No. } & \multirow{2}{*}{ Coating } & \multicolumn{2}{c}{ Microhardness, GPa } \\
\cline { 3 - 4 } & & initial & after testing \\
\hline 1 & $\mathrm{TiO}_{2}$ & 7.76 & 6.02 \\
\hline
\end{tabular}

Table 6. Friction coefficient of $\mathrm{TiO}_{2}$ coating

\begin{tabular}{cccc}
\hline \multirow{2}{*}{ No. } & \multirow{2}{*}{ Coating } & \multicolumn{2}{c}{ Friction coefficient } \\
\cline { 3 - 4 } & & with a $50 \mathrm{~N}$ load & with a $100 \mathrm{~N}$ load \\
\hline 1 & $\mathrm{TiO}_{2}$ & 0.63 & 0.92 \\
\hline
\end{tabular}

Considering the tougher conditions of dry friction, such results show a high resistance of the coating to wear, and it has a low friction coefficient under a load of $50 \mathrm{~N}$ (Tab.6). When a load is $100 \mathrm{~N}$, friction coefficient increases by $43 \%$ due to the wear of the coating and the formation of friction contact with the sample substrate. The microhardness after testing is decreased slightly (by $13 \%$ ) relative to the initial value.

\subsection{Photocatalytic Activity}

E. coli bacteria were set on meat-peptone agar and placed in thermostat at $37^{\circ} \mathrm{C}$ for 16 hours. The samples with $\mathrm{TiO}_{2}$ coating and bare stainless steel passed sterilization procedure. They were washed in Septolane disinfectant solution (concentration $1 \mathrm{~cm}^{3} /$ liter) and soaked for an hour. Next, they were washed with distillate and placed in sterilization bags in the autoclave at $180^{\circ} \mathrm{C}$ for 1 hour. After that, the grown colonies were transplanted onto samples coated with $\mathrm{TiO}_{2}$ and bare SS. With the help of UV lamp with a wavelength of $253.4 \mathrm{~nm}$, such two types of samples were exposed to UV irradiation with two different exposure times (10 and 20 minutes). Next was a flushing of a disposable transport tube with a swab of FL medical with Amies medium. The medium of endo was sown on a petri dish (16 h $37^{\circ} \mathrm{C}$ ) in the thermostat. 
The statistical results show a significant decrease of E. coli colonies with an increase in the irradiation time on samples coated with $\mathrm{TiO}_{2}$ (Fig.6.).

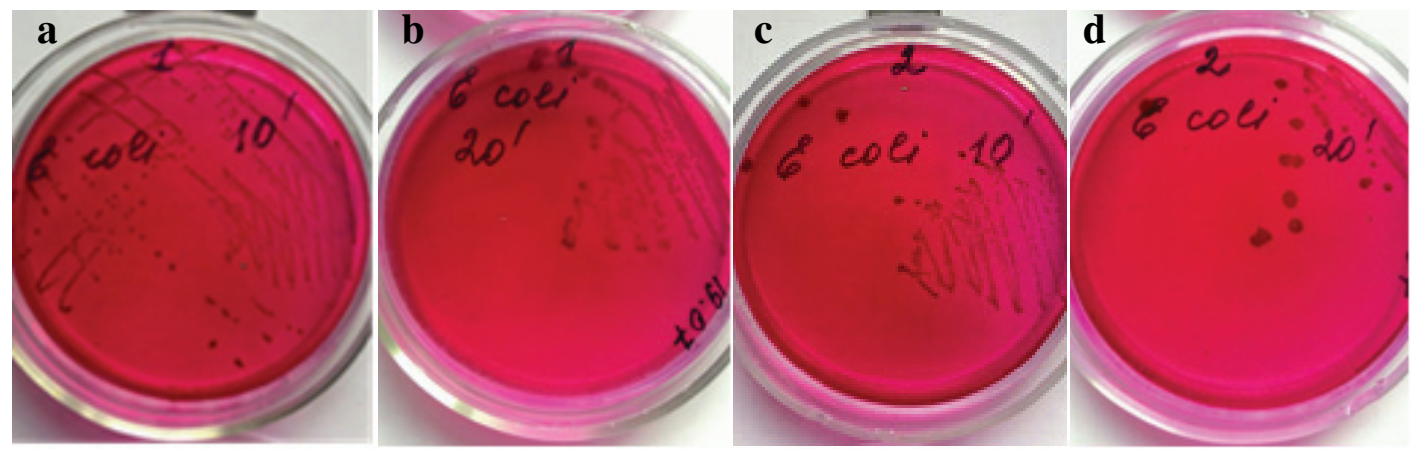

Figure 6. Elimination of E. coli colonies on bare AISI $430 \mathrm{SS}(\mathrm{a}, \mathrm{b})$ and $\mathrm{TiO}_{2}(\mathrm{c}, \mathrm{d})$ under UV light exposure during 10 and $20 \mathrm{~min}$.

\section{Conclusions}

1. $\mathrm{TiO}_{2}$ coatings on AISI 430 stainless steel were produced by the vacuum-arc deposition technique with the application of modified curvilinear magnetic filter allowed enhanced deposition rates up to $50 \mathrm{\mu m} /$ hour decreasing the amount of macroparticles.

2. XRD analysis revealed the existence of $\mathrm{TiO}_{2}$ phase. The chemical content was $\mathrm{Ti}=29.54$ at. $\%$ and $\mathrm{O}=69.40$ at. $\%$.

3. The coating had very low amount of macroparticles distributed over the surface and composed of relatively small globular $\mathrm{TiO}_{2}$ nanoparticles aggregated to form clusters.

4. According to nanohardness tests, the average value of nanohardness for $\mathrm{TiO}_{2}$ was $13.8 \mathrm{GPa}$ with the data spread $9.53 \%$. The average value of elastic modulus was $211.701 \mathrm{GPa}$. The spread of the data obtained does not exceed $7.71 \%$.

5. Considering the taught conditions of dry friction, the results show a high resistance of the coating to wear, and it has a low friction coefficient under a load of $50 \mathrm{~N}$.

6. The statistical results show a significant decrease of E.coli colonies with an increase in the irradiation time on samples coated with $\mathrm{TiO}_{2}$.

\section{References}

1. N. Berger-Keller, G. Bertrand, C. Filiatre, C. Meunier, C. Coddet, "Microstructure of Plasma sprayed titania coatings deposited from spray-dried powder", Journal Surface and Coatings Technology, vol. 168(2-3), pp.281290, 2003.

2. M. Anpo, "Preparation, Characterization, and Reactivities of Highly Functional Titanium Oxide-Based Photocatalysts Able to Operate under UV-Visible Light Irradiation: Approaches in Realizing High Efficiency in the Use of Visible Light," Bulletin of the Chemical Society of Japan, vol. 77, no. 8, pp. 1427-1442, 2004.

3. N.R. Mathews, E.R. Morales, M.A. Cortes-Jacome, J.A.T. Antonio, " $\mathrm{TiO}_{2}$ thin films - Influence of annealing temperature on structural, optical and photocatalytic properties", Journal of Solar Energy, vol.83, pp.1499-1508, 2009.

4. C.J. Chung, H.I. Lin, H.K. Tsou, Z.Y. Shi, J.L. He, "An antimicrobial $\mathrm{TiO}_{2}$ coating for reducing hospitalacquired infection", J Biomed Mater Res B Appl Biomater, vol. 85(1), pp. 220-4. 2008

5. N. Martin, C. Rousselot, D. Rondot, F. Palmino and R. Mercier, "Microstructure modification of amorphous titanium oxide thin films during annealing treatment," Journal Thin Solid Films, vol. 300, no.1-2, pp.113-121, 1997

6. M. Takeuchi, T. Yamasaki, K. Tsujimaru, "Preparation of $\mathrm{TiO}_{2}$ thin film photocatalyst on polycarbonate substrates by a RF-magnetron sputtering method", Journal of Chem. Lett., vol.35, pp. 904-905, 2006 
7. B.M. Reddy, G.K. Reddy, I. Ganesh, J.M.F. Ferreira, "Single step synthesis of nanosized CeO2-MxOy mixed oxides $(\mathrm{MxOy}=\mathrm{SiO} 2, \mathrm{TiO} 2, \mathrm{ZrO} 2$, and $\mathrm{Al} 2 \mathrm{O} 3)$ by microwave induced solution combustion synthesis: characterization and CO oxidation", Journal Mater. Sci, vol. 44, pp. 2743-2751, 2009

8. M.Thaidun, B. Venkata Rao, L. Raja Mohan Reddy, "Surface Morphological and Electrical Properties of Sputtered $\mathrm{TiO}_{2}$ Thin Films", Journal of Applied Physics, vol. 4, no. 1, pp. 25-29, 2013

9. M. Vishwas, S.K. Sharma, K. Narshimha Reao, S. Mohan,K.V.A. Gowda and R.P.S. Chakradhar, Spectrochim, "Influence of surfactant and annealing temperature on optical properties of sol-gel derived nano-crystalline $\mathrm{TiO}_{2}$ thin films", Spectrochimica Acta Part A: Molecular and Biomolecular Spectroscopy, vol. 75, no. 3, pp.1073$1077,2010$.

10. T.S. Skoblo, S.P. Romaniuk, A.I. Sidashenko, I.E. Garkusha, V.S. Taran, A.V. Taran, N.N. Pilgui "Strengthening method for thin-walled knives with multi-layer nanocoatings and quality assessment by nondestructive method", Journal of Advanced Microscopy Research. vol.13, no.3, pp. 333-338, 2018.

11. Valerij S. Taran, Rinat M. Muratov, and Anton V. Taran, "Spectrophotometric Evaluation of Reflection Coefficient of Thin Ti and TiN Coatings Depending on Deposition Method", Journal of Advanced Microscopy Research, vol. 12, pp. 203-206, 2017

12. V.S. Taran, I.E. Garkusha, "Recent developments of plasma-based technologies for medicine and industry", Journal Nukleonika., vol. 57, no.2, pp. 277-282, 2012

13. V.V. Gasilin, V.V. Kunchenko, Yu.N. Nezovybat'ko, A.V. Taran, V.S. Taran, V.I. Tereshin, O.M. Shvets, "Production of metal and dielectric films in a combined RF and arc discharge", J. Problems of Atomic Science and Technology, vol.1, pp.157-159, 2003

14. T.S. Skoblo, S.P. Romaniuk, A.I. Sidashenko, I.E. Garkusha, V.S. Taran, A.V. Taran, R.M. Muratov "Surface Morphology and Mechanical Properties of Vacuum-Arc Evaporated CrN and TiN Coatings on Cutting Tool", Journal of Advanced Microscopy Research, vol. 13, no.4, p.477-481, 2018. 